\title{
A Causal Relationship of Home Care Services on the Quality of Life among Survivors of Stroke in Thailand
}

\author{
Patoomthip ADUNWATANASIRI ${ }^{1}$, Siriorn SINDHU ${ }^{1, *}$, \\ Napaporn WANITKUN ${ }^{1}$ and Chukiat VIWATWONGKASEM ${ }^{2}$
}

\author{
${ }^{I}$ Faculty of Nursing, Mahidol University, Bangkok 10700, Thailand \\ ${ }^{2}$ Faculty of Public Health, Mahidol University, Bangkok 10400, Thailand
}

('Corresponding author's e-mail: siriorn.sin@mahidol.edu)

Received: 18 October 2019, Revised: 20 March 2020, Accepted: 22 April 2020

\begin{abstract}
Survivors of stroke suffer impairments associated with a complex need of care from healthcare services after being discharged from hospital and returning home, and these impairments affect the quality of their lives. This cross-sectional study, aimed at evaluating the pathways linking home care services, patient factors, and quality of life (QOL), was carried out by conducting interviews and questionnaires with stroke survivors at their homes. Simple random sampling was used to select the settings for data collection, and multi-stage sampling was used to select the samples. In all, 317 stroke survivors admitted to 13 hospitals in rural and urban setting were selected for participation in the study. The data obtained were analyzed by using Structural Equation Modeling (SEM). The hypothetical model demonstrated a good fit (chi-square $=15.299$, $\mathrm{df}=9, \mathrm{p}=0.083$, GFI $=0.98, \mathrm{CFI}=0.98$, RMSEA $=$ 0.047). Statistically significant explanatory variables for the home care service had a direct effect on perceived self-management support, functional status, and QOL $(\beta=0.39,0.12$ and 0.11 , respectively), while number of community supporters had a significant positive indirect effect on QOL through functional status $(\beta=0.13)$. The variables accounted for $56 \%$ of the variance in QOL. This finding could be used by policy makers to make important policy development in home care services and help improve health outcomes. In particular, it is also recommended that policy makers push for policies that encompass self-management support and community support groups among stroke survivors in community settings.
\end{abstract}

Keywords: Home care services, Stroke, Self-management, Quality of life

\section{Introduction}

Stroke is one of the leading causes of the public health burden, whereby 16.9 million people have $1^{\text {st }}$ strokes, and 5 million having their $1^{\text {st }}$ ever strokes become permanently disabled [1]. Along with the impactful physical burden, stroke also carries a large economic burden, especially after the survivors return into the community with functional impairment. The costs of direct and indirect lifetime stroke expenditures due to lost earnings and informal care have been reported to be 3.4 times higher than the critical care period in hospitals [2]. Most patients with stroke have mobility problems (58.4\%), followed by fatigue, inattention, falls, memory problems, pain, emotional problems, and incontinence $(51.7,44.7$, $43.9,42.8,39.5,38.4$, and $37.2 \%$, respectively), thereby creating burdens from the disease [3].

Access to rehabilitation services both in-hospital and in post-acute care settings in communities is limited and fragmented, even in the best of the public health systems around the globe [4]. Previous studies have suggested that post-acute care service in an institution provided with a coordinator by a multidisciplinary team is the best model for improved functional outcome among stroke survivors in the 
community [5,6]. However, developing countries, including Thailand, take advantage of access to inpatient rehabilitation only after discharge to home at $31.2 \%$ [7], while $44 \%$ of all stroke disabilities occur at home within three months post-discharge [8]. When comparing these findings with the status of post-stroke care in the United States, over $70 \%$ of stroke cases have access to more than 1 type of postacute care setting [9]. Many patients and their caregivers in developing countries will then have to fend for themselves, based on whatever facilities are available in their communities, and seek out treatment from their primary care providers.

In Thailand, home care service policy plays a key role in community-based care for stroke patients. Most of these patients have been found to have a high level of dependence, being unable to meet their self-care needs unaided, and face barriers to access comprehensive stroke centers found only at tertiary public sector hospitals in Bangkok and in a few of the larger provincial hospitals. Hence, home care service is arranged to handle and support post-stroke rehabilitation and promote good quality of life, with efforts aimed at arranging healthcare teams and applying self-management to community-based care. Primary care teams are usually composed of a general practitioner (GP) or family medicine (FM) specialist and nurses, as well as other health professionals who provide community-based care to stroke patients. Primary care clusters are set as follows: Population in the community equal to 1:10,000 people to provide equal access to services. However, according to the current situation, the primary care teams, led by registered nurses (RNs), have been found to be instrumental in providing post-stroke care in community and home-based services for last 2 decades, because there is a shortage of FM specialists to meet community needs, and family medicine is mostly found in tertiary public sector hospitals or comprehensive stroke health centers [10]. Thus, a clear pathway or component of existing home care, appropriate service design to suit the health situations of stroke survivors in the community, and all other issues associated with health outcomes ought to be well-understood in order to help policymakers.

In developed countries, studies aimed at comparing health outcomes and satisfaction with services among patients and caregivers between home health versus hospital-based care and outpatient rehabilitation found patients who received hospital-based care through home care to have less disease severity. Furthermore, caregivers were satisfied with home-based care services, cost savings, and patients' well-being, particularly in the first 3 months post-stroke [11,12]. According to evidence-based practice, the process of care to support the following self-management strategies has positive influence in reducing disability and improving QOL in stroke survivors [13]. Cramm and Nieboer conjectured that patients' perceptions of self-management support enabled patients to make health-related decisions to achieve skills and capacities to sustain wellbeing. In addition, confidence in health management was found to be associated with improved well-being with statistical significance [14]. Understanding the perspectives of home care patients with stroke is essential in evaluating chronic care and ensuring that both care and health outcome efforts are aligned with the patients' needs.

Patients with stroke have physical impairments, uncontrolled health conditions, and low quality of life [15]. Quality of life (QOL) is the proximal goal of health in survivors, and a better QOL is perceived by stroke survivors who, in their daily living, are dependent on the availability of social connections and use of both home care services and rehabilitation $[16,17]$. If there were enough home care services related to the improvement of health outcomes, there would be a reduction in healthcare resource utilization for in-patient rehabilitation, particularly among stroke survivors in community settings with complex care needs [18]. The aim of this study was to determine the hypothetical relationships among home care services, perceived self-management support, self-management ability, patient factors, and QOL among stroke survivors in Thailand.

\section{Materials and methods}

\section{Study design and participants}

This cross-sectional study was conducted from September 2017 to March 2018. The population was male and female, after ischemic or hemorrhagic stroke patients living in the Bangkok Metropolitan area and 4 provinces from each region. The participants were randomly selected and enrolled in a convenience sample of 350 post-stroke patients who had been treated and discharged for a period of at least 3 months 
http://wjst.wu.ac.th

to 1 year. The inclusion criteria required that the participants be adults (18 years or older), be patients having had the $1^{\text {st }}$ stroke confirmed by a physician who were living in a community, and be patients who remained functionally impaired (modified Rankin Scale [mRS] 2 - 5). The researcher would like to add that only those participants who were contactable on the day of recruitment at each venue were included. Patients who had previous histories of psychotic and mental disorders, and those who were at the end of life due to diseases, such as stroke victims with final-stage cancers, were excluded, as were those who were unable to complete the questionnaires.

Of the 350 participants in this study, 321 were interviewed ( 29 could not be contacted by phone or at their current addresses at the time). An adequate sample size of 10 - 15 times the estimated parameter was appropriate [19]. This research had 19 estimated parameters and assumed an attrition rate of $40 \%$. Thus, the effect size was 300 - 400 to ensure degree of freedom and fit of the model according to the number of participants.

In the multistage random sampling procedure, all regions and the Bangkok Metropolitan area were selected. The researcher performed the following: (a) determining the need for both rural and urban participants who were chosen from four provinces; (b) selecting hospitals based on hospital type (university, local, community hospitals). The researcher surveyed the hospitals located in rural areas consisting of 4 provinces from each region and the Bangkok Metropolitan area. The researcher employed simple random sampling to the selection of one province in each of the regions of Thailand. The selection of hospitals in each province consisted of one tertiary public sector hospital or one university hospital and 1 - 2 local and community hospitals. For the Bangkok Metropolitan area, the researcher employed simple random sampling to the selection of 5 hospitals in Bangkok under the Ministry of Public Health, other Ministry hospitals, and hospitals under the Bangkok Metropolitan Administration; (c) enrolling participants who had been discharged from 13 hospitals to home care services at community-based health centres within the District Health System; (d) choosing respondents by a probability proportion sample from each of the 5 regions that was appropriate for an unequal number of stroke patient populations in each clinic [20] (Table 1).

Table 1 Probability proportional calculated size sampling of the participants.

\begin{tabular}{|c|c|c|c|c|c|c|}
\hline $\mathbf{A}$ & $\mathbf{B}$ & $\mathbf{C}$ & D & $\mathbf{F}$ & $\mathbf{G}$ & $\mathbf{H}$ \\
\hline Cluster & Size (a) & $\begin{array}{l}\text { Cumulative } \\
\text { sum }\end{array}$ & $\begin{array}{l}\text { Clusters } \\
\text { sampled }\end{array}$ & $\begin{array}{c}\text { Individual } \\
\text { sample per } \\
\text { cluster } \\
\left(\mathrm{C}=\mathbf{a}^{*} \text { total }\right. \\
\text { sample / b) }\end{array}$ & $\begin{array}{l}\text { Individual } \\
\text { sample per } \\
\text { cluster after } \\
\text { add } 40 \% \\
\text { attrition rate }\end{array}$ & $\begin{array}{c}\text { Individual } \\
\text { sample per } \\
\text { cluster } \\
\text { (1 cluster not } \\
\text { less than } 30 \text { ) }\end{array}$ \\
\hline $1^{\mathrm{a}}$ & 1,009 & 1,009 & $4,158.4$ & 12 & 5 & 30 \\
\hline $2^{b}$ & 2,372 & 3,381 & $8,316.8$ & 27 & 22 & 38 \\
\hline $3^{\mathrm{c}}$ & 2,000 & 5,381 & $12,475.2$ & 23 & 10 & 33 \\
\hline $4^{d}$ & 3,104 & 8,485 & $16,633.6$ & 36 & 15 & 51 \\
\hline $5^{\mathrm{e}}(\mathrm{d})$ & 12,307 & 20,792 (b) & 20,792 & 142 & 56 & 198 \\
\hline Total & 20,792 (b) & 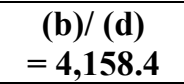 & & & & $=350$ \\
\hline
\end{tabular}

Note. (a) $=$ Number of stroke patients according to each region in 2015 - 2016, ${ }^{a}$ Phrae province;

${ }^{\mathrm{b}}$ Sakonakorn province; ${ }^{\mathrm{c}}$ Pathumthani province; ${ }^{\mathrm{d}}$ Nakhon Si Thammarat province; ${ }^{\mathrm{e}}$ Bangkok Metropolitan.

After obtaining formal permission from the participant hospitals' ethics committees, the researcher directly coordinated with the medical records officer and the director of nursing in the primary care departments of each hospital, all of whom were approached for data collection in the community settings. The researcher prepared research assistants (RAs) who helped collect the data provided on nursing care in stroke units or primary care in each setting for more than 2 years. The RAs were trained and trial 
practiced with the researcher after the ethics committees had granted approval by using questionnaires with patients who had characteristics similar to the sample group. The discrepancies were resolved by inter-rater reliability ranging from 0.930 to 0.982 for the different instruments. Phone calls were made by research assistants who were ordinary home visitors to invite the participants, with plans to visit patients' homes. When patients or family caregivers allowed visiting at home, the researcher obtained permission and visited homes. Face-to-face interviews took place in the patients' own homes by the researcher and/or research assistants. Ethical approval was obtained from the ethics committees of the Faculty of Medicine Siriraj Hospital, Mahidol University (COA No. Si 527/2017), and local hospitals. Then, informed consent was obtained from each participant.

\section{Study instruments}

1) Home care service set of questionnaires are defined as a structure pattern of formal support from the primary care team, received by patients after discharge to return to the community. The items in the research instruments were developed based on the review of the relevant literature [21,22], and the measurement model was decided upon by confirmatory factor analysis. The input from home care services included three items: the total number of providers involved, the number of home visits, and the length of hours spent in treatment per visit. This was assessed by asking either stroke patients or caregivers who had been in contact with home services within the past three months to one year, and was recorded as a 'yes', 'no', or 'don't know' response. The number of providers involved and the number of home visits were calculated by adding up the 'yes' responses. As shown in Table 3, the 3 services for home care had a loading of preferably $>0.07$, and the composite reliability $(\mathrm{CR})$ of variable measurement exceeded 0.70 . Moreover, the convergent validity and averages of variance extracted (AVE) were greater than $50 \%$ of the cut-off value, thereby indicating adequate validity [19].

2) Perceived self-management support was measured by using the Patient Assessment of Chronic Illness Care (PACIC) questionnaire [23]. This instrument (PACIC) was designed to assess chronic illness patients' confidence and perspectives by focusing on the receipt of patient-centered care and selfmanagement behaviors. The variable measurement criterion was composed of 20 items. Higher scores implied patient perception of greater involvement in self-management or receipt of chronic illness care. Cronbach $\alpha$ was 0.90 , which displayed excellent internal consistency.

3) The instrument that was used to mine data on self-management ability was the Southampton Stroke Self-Management Questionnaire (SSSMQ) [24]. The SSSMQ is composed of 28 items that measure stroke self-management competency, which are the features an individual requires to have the skills and ability to manage health and well-being following a stroke. A higher score indicates greater self-management ability, and Cronbach $\alpha$ was 0.80 , thereby expressing adequate internal consistency.

4) Functional status was measured by using modified Rankin Scale (mRS) for classifying the neurological impairments that impact on degree of disability after stroke. A high score of Grades 2 - 5 means slight to severe disability, and Grade 6 means death. Therefore, this study used a ranking scale of $2-5$.

5) The Stroke Specific Quality of Life Scale (SS-QoL) short version was used to measure QOL [25]. The SS-QoL is a self-reporting questionnaire comprising 12 items that require responses on a 5point scale, ranging from 1 (could not do it at all/total help) to 5 (no trouble at all/no help needed). In the present study, the researcher polished the statements of the Thai version, using additional translation and the back-translation technique. Reliability testing was done with the Cronbach's coefficient alpha at 0.84, thereby indicating adequate internal consistency.

\section{Statistical analyses}

Structural equation model with a maximum likelihood estimation method was used to evaluate the fitness of the hypothesized model based on the following multiple criteria: $\chi 2$ test, goodness of fit index (GFI), and adjusted GFI (AGFI) were greater than 0.95, normed-fit index (NFI) $>0.95$, standardized root mean square residual $(\mathrm{SRMR})<0.08$, and root mean square error of approximation (RMSEA) $<0.07$ [26]. One of the notable applications of SEM is that it can be applied in exploring the relationships among latent constructs which are indicated by multiple measures. 


\section{Results and discussion}

\section{Demographic characteristics of participants}

From 321 questionnaire sheets survey, 317 were appropriately analyzed. Response rate was $91.71 \%$ (four of which had inadequate data on major variables to analyze because of the extreme outliers found). Most of the participants were male (57.4\%), with a mean age of 64.16 years (SD 11.83 ). Only $36 \%$ had finished a bachelor's degree or higher. Around $19.9 \%$ of them had not returned to work after suffering from stroke. More than $50 \%$ of them had moderate to severe disability (mRS 3 - 5) (Table 2).

Table 2 Demographic characteristics of participants $(n=317)$.

\begin{tabular}{ccc}
\hline Variables & Categories & $\mathbf{n}(\mathbf{\%})$ \\
\hline Gender & Male & $182(57.4)$ \\
Age (yrs.) & $39-64$ & $167(52.7)$ \\
& $>64$ & $150(47.3)$ \\
Education level & Illiterate & $24(7.6)$ \\
& Primary or secondary or vocational schools & $179(56.5)$ \\
Employment status & Bachelor's degree or higher & $114(36)$ \\
& Retired & $40(12.6)$ \\
& Unemployed/Homemaker & $175(55.2)$ \\
Functional status (mRS) & Job loss due to illness & $63(19.9)$ \\
& Continuously employed & $39(12.3)$ \\
& 2 (Slight disability) & $136(42.9)$ \\
& 3 (Moderate disability) & $117(36.9)$ \\
Duration of disease (month) & 4 (Moderately severe disability) & $43(13.6)$ \\
& 5 (Severe disability) & $21(6.6)$ \\
Access to rehabilitation after & 3 - 6 & $147(46.4)$ \\
discharge & 6 - 12 & $170(53.6)$ \\
& Family or caregiver at home & $182(57.4)$ \\
& Self-care at home & $74(23.4)$
\end{tabular}

Note. ${ }^{\mathrm{a}} \mathrm{mRS}=$ modified Ranking Scale

Home care services and variables related to QOL

All of the participants had received input from home care services since hospital discharge (the mean number of providers involved was 2.73; SD 1.73). Overall, the healthcare providers spent an average of $27.73 \mathrm{~min} /$ visit with stroke survivors. The home care services most commonly provided after discharge were rendered by nurses $(57.7 \%)$, physiotherapists $(38.5 \%)$ and community nurses $(26.8 \%$ ). Approximately $56.5 \%$ received neighbor or voluntary support in their communities (Table 3). Most of the participants had received activities support from health volunteers, including purchasing food or preparing meals $(84.2 \%)$, daily living $(59.9 \%)$ and social participation in the community $(58.7 \%)$. The mean PACIC score was 3.49 (SD 0.63) and the SSSMQ score was 4.01 (SD 0.35), while the SS-QoL score was 3.62 (SD 0.64). 
http://wjst.wu.ac.th

\section{A causal relationship between home care services and patient's factors and QOL}

Structural equation model was performed to examine the effects of the home care services and patients' factors on QOL by using the program AMOS version 23. Verification of the fitness of the hypothesized model is shown in Figure 1. Since $\chi^{2}$ was 15.299, which was lower than twice the degree of freedom $(\mathrm{GFI}=0.98, \mathrm{CFI}=0.98, \mathrm{NFI}=0.96, \mathrm{SRMR}=0.04$, and RMSEA $=0.047)$, it satisfied the fact that the model provided a good fitness to the data. The model indicated that the home care services had a direct effect on perceived self-management support $(\beta=0.39, p=0.007)$, functional status $(\beta=0.12, p=$ $0.006)$, and QOL $(\beta=0.11, p=0.004)$. Perceived self-management support had a direct effect on QOL $(\beta$ $=0.15, \mathrm{p}=0.006)$, and also an indirect effect on functional status via self-management ability $(\beta=0.05$, $p=0.002)$. Age had no effect on functional status or QOL. Meanwhile, number of community supporters had a direct effect on functional status $(\beta=-0.18, p=0.004)$, and had an indirect effect on QOL via functional status $(\beta=0.13, p=0.003)$. The results are shown in Table 4 .

Table 3 Descriptive statistics of variables and home care service factor loading.

\begin{tabular}{|c|c|c|c|c|c|}
\hline Variables & Categories & Mean \pm SD & Loading & $\mathbf{C R}^{\mathrm{a}}$ & $\mathbf{A V E}^{\mathrm{b}}$ \\
\hline \multirow[t]{13}{*}{ Home care service } & Number of providers involves & $2.73 \pm 1.73$ & 0.82 & 0.90 & 0.76 \\
\hline & Nurse n (\%) & $183(57.7)$ & & & \\
\hline & Physiotherapist & $122(38.5)$ & & & \\
\hline & Community nurse & $85(26.8)$ & & & \\
\hline & Nutritionist & $55(17.4)$ & & & \\
\hline & $\begin{array}{l}\text { Thai traditional medicine } \\
\text { specialist }\end{array}$ & $52(16.4)$ & & & \\
\hline & Pharmacist & $30(9.5)$ & & & \\
\hline & Family medicine specialist & $26(8.2)$ & & & \\
\hline & Nurse case manager & $25(7.9)$ & & & \\
\hline & Social worker & $12(3.8)$ & & & \\
\hline & Psychiatric nurse & $1(0.3)$ & & & \\
\hline & Number of home visits & $2.40 \pm 1.76$ & 0.81 & & \\
\hline & Length of hour treatment/visit & $27.73 \pm 15.79$ & 0.78 & & \\
\hline \multicolumn{2}{|c|}{ Number of community supporters } & $1.29 \pm 1.07$ & & & \\
\hline & Neighbors/voluntary n (\%) & $179(56.5)$ & & & \\
\hline \multicolumn{6}{|c|}{ Support groups } \\
\hline & Village health volunteer & $125(39.4)$ & & & \\
\hline & Community leader & $45(14.2)$ & & & \\
\hline & $\begin{array}{l}\text { Complementary medicine } \\
\text { specialist }\end{array}$ & $35(11)$ & & & \\
\hline & Local government support & $19(6)$ & & & \\
\hline & Monk/imam & $10(3.2)$ & & & \\
\hline \multicolumn{2}{|c|}{ Perceived self-management support $(\mathrm{PACIC})^{\mathrm{C}}$} & $3.49 \pm 0.63$ & & & \\
\hline \multicolumn{2}{|c|}{ Self-management ability (SSSMQ) ${ }^{\mathrm{d}}$} & $4.01 \pm 0.35$ & & & \\
\hline \multirow[t]{3}{*}{ Quality of life } & $\mathrm{SS}-\mathrm{QoL}^{\mathrm{e}}$ & $3.62 \pm 0.64$ & & & \\
\hline & Physical & $3.40 \pm 1.17$ & & & \\
\hline & Psychosocial & $4.12 \pm 0.60$ & & & \\
\hline
\end{tabular}

Note. ${ }^{\mathrm{a}} \mathrm{CR}=$ composite reliability; ${ }^{\mathrm{b}} \mathrm{AVE}=$ average variance extracted; ${ }^{\mathrm{c}} \mathrm{PACIC}=$ the Patient Assessment of Chronic Illness Care questionnaire; ${ }^{\mathrm{d}} \mathrm{SSSMQ}=$ the Southampton Stroke Self-Management

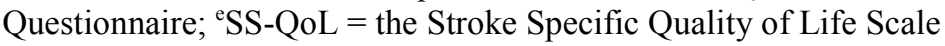




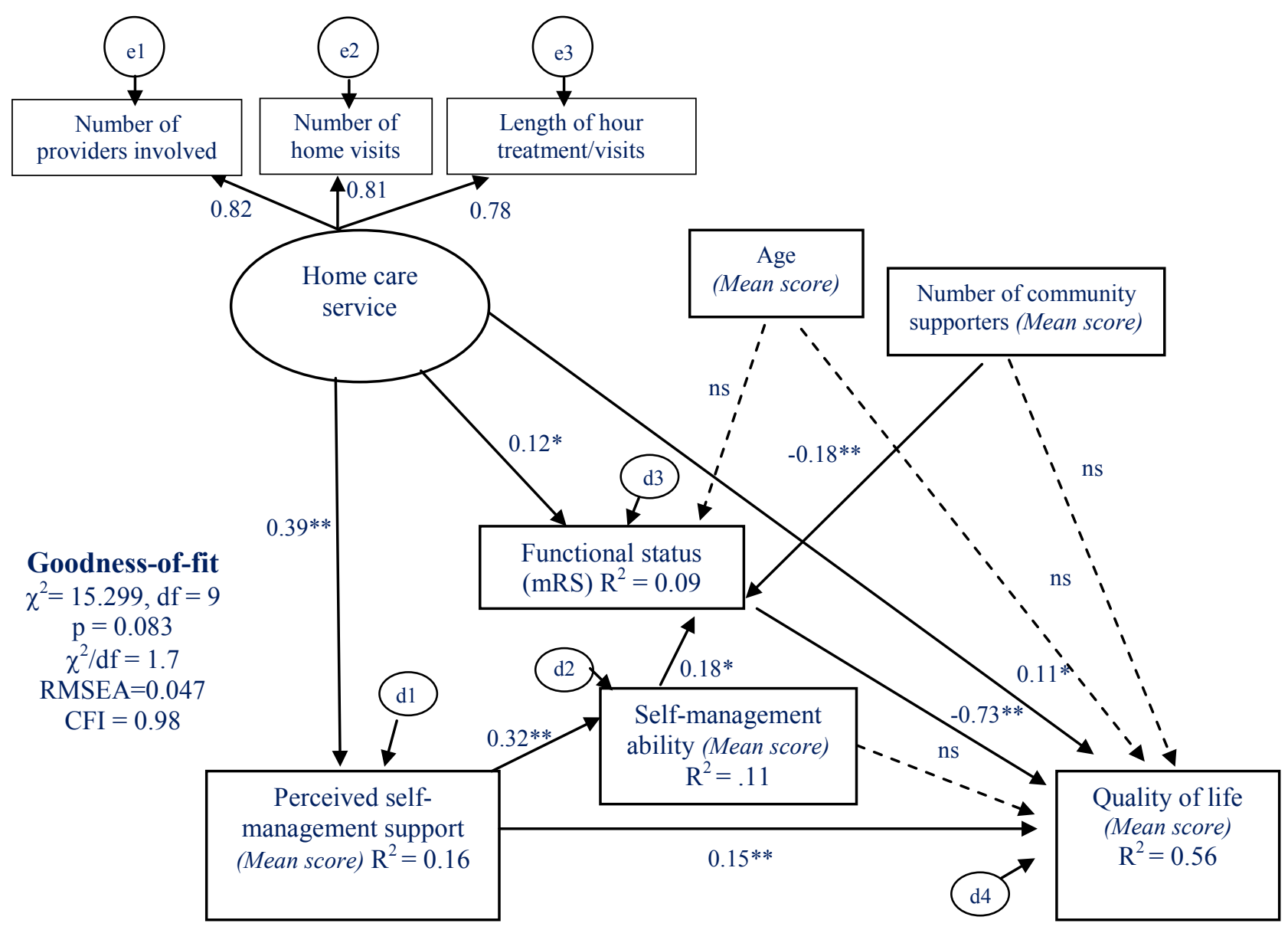

Figure 1 A causal relationship between home care service and patients' factors on QOL.

Note. $\mathrm{ns}=$ not significant; $\mathrm{R}^{2}=$ percentage of variance explained in each endogenous variable.

$* * \mathrm{p} \leq 0.01$ 
http://wjst.wu.ac.th

Table 4 Direct, indirect, and total effects of causal relationship among survivors of stroke.

\begin{tabular}{llccc}
\hline \multicolumn{1}{c}{ Endogenous variables } & Exogenous variables & $\begin{array}{c}\text { Standardized } \\
\text { direct } \\
\text { effects (p) }\end{array}$ & $\begin{array}{c}\text { Standardized } \\
\text { indirect } \\
\text { effects (p) }\end{array}$ & $\begin{array}{c}\text { Standardized } \\
\text { total } \\
\text { effects (p) }\end{array}$ \\
\hline $\begin{array}{l}\text { Perceived self-management } \\
\text { support }\end{array}$ & Home care service & $0.39(0.007)$ & - & $0.39(0.007)$ \\
Self-management ability & Home care service & - & $0.12(0.002)$ & $0.12(0.002)$ \\
& Perceived self-management support & $0.32(.002)$ & - & $0.32(0.002)$ \\
Functional status & Home care service & $0.12(0.006)$ & $0.02(0.002)$ & $0.16(0.004)$ \\
& Perceived self-management support & - & $0.05(0.002)$ & $0.05(0.002)$ \\
& Age & $0.06(0.164)$ & - & $0.06(0.164)$ \\
QOL & Number of community supporters & $-0.18(0.004)$ & - & $-0.18(0.004)$ \\
& Home care service & $0.11(0.004)$ & $-0.064(0.105)$ & $0.048(0.350)$ \\
& Perceived self-management support & $0.15(0.006)$ & $-0.056(0.008)$ & $0.09(0.028)$ \\
& Age & $-0.03(0.495)$ & - & $-0.03(0.495)$ \\
& Number of community supporters & $0.07(0.102)$ & $0.13(0.003)$ & $0.20(0.005)$ \\
& Functional status & $-0.73(0.003)$ & - & $-0.73(0.003)$ \\
\hline
\end{tabular}

\section{Mediating effect of functional status}

The model of this research proved that there was a mediating effect of functional status between number of community supporters and QOL. The researcher used the Sobel (z) statistic [27], and the results showed that value exceeded $1.96(\mathrm{z}=2.979, \mathrm{p}=0.003)$; therefore, these findings supported the notion that there was an indirect effect of number of community supporters through functional status on QOL.

\section{Discussion}

These findings provided a clear causality rooted in the fact that positive effects of home care service could be fostered through patient-centered activities that could be incorporated in self-management support to improve health outcomes and QOL.

The mean QOL was 3.62 (SD 0.64), which was close to the developed countries in Asia [28] and European countries [29]. The majority of participants had considerable experience with care provided by nurses/community nurse practitioners, physiotherapists, nutritionists, and Thai traditional medicine specialists visiting at home, with an average of 3 times of visiting at home, and the mean time spent in providing care was $27.73 \mathrm{~min}$. This finding is consistent with another study conducted in Asia about the home-based services provided by a nurse and care helper; an average of 5 times of home visits by a nurse, an average of 22 times of home visits by a care helper, and physicians provided services at an average of only one home visit. According to the findings, the patients who received home-based services were significantly and positively associated with physical and psychosocial functioning after 1 year following stroke [30]. In comparison, data showed that, in European countries, these services usually helped reduce disabilities and promote good quality of life for most patients who received them from a general practitioner (GP) [21]. This means that the patients who received regular home visits from nurses and healthcare professionals, with an average amount of time spent $(27.73 \mathrm{~min})$ spent on providing treatment and information, were more likely to have confidence in their ability to perform stroke-related health behaviors.

This study also inferred that higher perceived self-management support from services was strongly related to good QOL [31] and with findings from other empirical studies. It was also noted that higher perceived self-management support was directly associated with performance ability, management, facilitation, and maintenance of health outcomes [32]. In contrast, a systematic review demonstrated that there was a significant relationship between self-management support and patient-level health outcomes in patients predominantly with diabetes and hypertension [33]. This finding can be explained through the lens of the Precede-Proceed model on health, which is also related to the process of care in service 
delivery, by encouraging practitioners to view overall health and individual health behaviors within the overall ecosystem of health determinants and to continually follow those conditions [34]. Nurses are the leading home visitors and advocates of behavioral modification involving the management of health conditions, advice, and setting goals to meet patients' needs with family members and community supporters or volunteers. Furthermore, the findings revealed that the participants received specific care during the past 3 - 12 months after stroke according to the patients' points of view by using PACIC measurement. The mean PACIC score was 3.49, which was higher than the mean score of developed countries [35]. The results of the present study explained that nurses and healthcare teams providing home-based care have close proximity to patients and their families and receive the trust of these people, thereby building confidence in health management, rehabilitation, continuity of service provision, and follow-up. Arranging home care services provided by nurses can result in satisfaction, reduce readmission rates, and yield cost benefits [36,37].

A surprising finding was that number of community supporters, such as neighbors or voluntary support groups, village health volunteers, and other care providers or health support groups, have a significant indirect impact on QOL. In other words, when a patient's physical functioning was worse (high mRS scales), more group supporters had more of an impact reduction in disability and enhanced the QOL. Thus, the researcher also explored the functional status as a mediator of the relationship between number of community supporters and QOL. Our results were consistent with those of previous studies indicating that family members and the active involvement of home-based services after stroke participated in various care activities support, which helped stroke patients improve functional status and QOL [38].

It suffices to note here that previous studies were unclear on evidence of any relationships or effects of home care service and QOL to post-stroke patients. It could, therefore, be concluded that home care services in Thailand could effectively support stroke survivors in situations when GPs are insufficient in rural and urban settings. A possible reason for these discrepant findings is that the role of nurses who work in community health centres not only involves direct nursing care, but also encompasses disease management, rehabilitation, and coordination with primary care providers and community health volunteers who are involved in promoting meet physical and psychosocial care needs after stroke [39].

Therefore, policymakers should arrange training to enhance the skills of nurses and healthcare teams providing services for community-based patients, with emphasis placed on promoting continued rehabilitation to reduce disabilities and promote self-management with sustainability, so patients can make decisions for good health behavior. The Thai context of caring for stroke survivors with functional impairment at home not only involves community services, but also community supporters or group volunteers who are involved in promoting seamless life in post-stroke care. Policymaking should consider contribution and training for community volunteers to gain knowledge and skills in the rehabilitation of stroke patients for the times where families are unable to continually provide care and rehabilitation, which will promote rapid recovery and reduce disabilities.

Our study also indicated that home care services had no indirect significant effect on QOL via perceived self-management support. A possible reason of these discrepant findings could be reflective of the fact that patients with stroke had complex health conditions and needs. Other types of transitional care, such as sufficient integration of professionals in healthcare and social workers with necessary community resources, were more effective and improved health outcomes [40]. A comparative study between formal support services in developed countries revealed that the mean of service involvement was 5.4 services and sufficient time was allocated for taking care of stroke survivors and the caregivers [21]. First, it was observed that most common health services after patients were discharged included GPs $(90 \%)$ and community nurses $(73 \%)$. In contrast, however, in Thailand, healthcare resources that promote and provide supportive care in the community are limited. Secondly, lack of service provision was expressed by care training with caregivers, speed of response after hospital discharge, and initiating rehabilitation at home [41]. Stroke patients still suffer multiple neurological impairments, and these impacts adversely affect the physical and psychosocial well-being of the patients after discharge.

The present study had strengths accruing from its timeliness, scope, and the nature of its data. This study was based on the representative sampling and sample of home care services with patients who lived 
http://wjst.wu.ac.th

in the communities of the 5 regions of Thailand, including the Bangkok Metropolitan area. This was a profound strength, given that the data collection was primarily based on real situations and feedback on health outcomes, in terms of the big picture of existing home care support for stroke survivors at home. Although the study had some limitations in the standard measure of home care services, the measurement of the data construct had good representation validity. Moreover, there was a $10 \%$ non-respondent rate following hospital discharge who could not be contacted. In previous studies on community-dwelling by White et al. [42] and Mahesh et al. [43], the non-respondent rates were of $10-20 \%$. This was due to patient hospital discharge missing correct registration information or the patients emigrating [42,43]. Therefore, we suggest that the attrition rate can rise up $40 \%$ in a community setting.

\section{Conclusions}

The model of the study suggested that home care services working was regarded as the key causeand-effect on QOL. Moreover, perceived self-management support from healthcare providers was a crucial link between home care services and health outcomes. The foregoing suggestions are made bearing in mind that, in Thailand, the QOL is still lower than that of the same type of patients in highincome countries, especially in the physical domain, because the institutional rehabilitation services that provide active treatment by multidisciplinary teams have limited access for patients with complex conditions. Therefore, patients of stroke who have low QOL need to access such services in order to meet their needs receive enough support and perceived self-management ability to maintain health conditions. It seems that, not only though home care services, but also group volunteers and local government, are involved in promoting seamless life poststroke care. More research is needed to better understand how to improve the perceived process of service support and benefit from the services provided.

\section{Acknowledgements}

The researcher would like to thank all respondents and all staff of the primary care service departments. The researcher hereto discloses that fund support was received for the research, authorship, and publication of this article from the National Research Council of Thailand, December 2017.

\section{References}

[1] World Health Organization. The global burden of disease: 2004 update, Available at: https://www.who.int/healthinfo, accessed July 2016.

[2] BM Demaerschalk, HM Hwang and G Leung. US cost burden of ischemic stroke: A systematic literature review. Am. J. Manag. Care 2010; 16, 525-33.

[3] C McKevitt, N Fudge, J Redfern, A Sheldenkar, S Crichton, AR Rudd, A Forster, J Young, I Nazareth, LE Silver, PM Rothwell and CD Wolf. Self-reported long-term needs after stroke. Stroke 2011; 42, 1398-403.

[4] JI Cameron, C Tsoi and A Marsella. Optimizing stroke systems of care by enhancing transitions across care environments. Stroke 2008; 39, 2637-43.

[5] YC Wang, F Yang, H Shi, CM Yang and H Hu. What type of transitional care effectively reduced mortality and improved ADL of stroke patients? A meta-analysis. Int. J. Environ. Res. Public. Health 2017; 14, 510.

[6] CL Lai, MM Tsai, JY Luo, WC Liao, PS Hsu and HY Chen. Post-acute care for stroke: A retrospective cohort study in Taiwan. Patient. Prefer. Adherence 2017; 11, 1309-15.

[7] A Riewpaiboon, W Riewpaiboon, K Ponsoongnern and BV den Berg. Economic valuation of informal care in Asia: A case study of care for disabled stroke survivors in Thailand. Soc. Sci. Med. 2009; 69, 648-53.

[8] S Muengtaweepongsa, P Dharmasaroja and U Kummark. Outcomes of intravenous thrombolytic therapy for acute ischemic stroke with an integrated acute stroke referral network: Initial experience of a community-based hospital in a developing country. J. Stroke Cerebrovasc. Dis. 2012; 21, 42-6. 
http://wjst.wu.ac.th

[9] MB Buntin, CH Colla, P Deb, N Sood and JJ Escarce. Medicare spending and outcomes after postacute care for stroke and hip fracture. Med. Care 2010; 48, 776-84.

[10] Strategy and Planning Division, Ministry of Public Health. The report on public health resources, Available at: http://bps.moph.go.th, accessed February 2020.

[11] H Wang, ME Sandel, J Terdiman, MA Armstrong, A Klatsky, M Camicia and S Sidney. Postacute care and ischemic stroke mortality: Findings from an integrated health care system in Northern California. J. Inj. Funct. Rehabil. 2011; 3, 686-94.

[12] S Dewilde, L Annemans, A Peeters, D Hemelsoet, Y Vandermeeren, P Desfontaines, R Brouns, G Vanhooren, P Cras, B Michielsens, P Redondo and V Thijs. The relationship between home-time, quality of life and costs after ischemic stroke: The impact of the need for mobility aids, home and car modifications on Home-time. Disabil. Rehabil. 2020; 42, 419-25.

[13] G Warner, T Packer, M Villeneuve, A Audulv and J Versnel. A systematic review of the effectiveness of stroke self-management programs for improving function and participation outcomes: Self-management programs for stroke survivors. Disabil. Rehabil. 2015; 37, 2141-63.

[14] JM Cramm and AP Nieboer. The relationship between self-management abilities, quality of chronic care delivery, and wellbeing among patients with chronic obstructive pulmonary disease in The Netherlands. Int. J. Chron. Obstruct. Pulmon. Dis. 2013; 8, 209-14.

[15] WE Haley, DL Roth, B Kissela, M Perkins and G Howard. Quality of life after stroke: A prospective longitudinal study. Qual. Life. Res. 2011; 20, 799-806.

[16] T Tse, SZ Binte Yusoff, L Churilov, H Ma, S Davis, GA Donnan and LM Carey. Increased work and social engagement is associated with increased stroke specific quality of life in stroke survivors at 3 months and 12 months post-stroke: A longitudinal study of an Australian stroke cohort. Top. Stroke Rehabil. 2017; 24, 405-14.

[17] K Sayuri and K Masako. Evaluation of health-related quality of life associated with provision of healthcare to stroke patients living at home in Japan. Health 2015; 7, 1105-13.

[18] L Chen, JW Sit and X Shen. Quasi-experimental evaluation of a home care model for patients with stroke in China. Disabil. Rehabil. 2016; 38, 2271-6.

[19] JF Hair, WC Black, BJ Babin and RE Anderson. Multivariate data analysis. Pearson, New Jersey, 2010, p. 642-91.

[20] A Bierrenbach. Steps in applying Probability Proportional to Size (PPS) and calculating basic probability weights, Available at: https://www.who.int/advisory_bodies, accessed April 2016.

[21] C Simon, S Kumar and T Kendrick. Formal support of stroke survivors and their informal carers in the community: A cohort study. Health Soc. Care Commun. 2008; 16, 582-92.

[22] HC Huang, YC Huang, MF Lin, WH Hou, ML Shyu, HY Chiu and HJ Chang. Effects of homebased supportive care on improvements in physical function and depressive symptoms in patients with stroke: A meta-analysis. Arch. Phys. Med. Rehabil. 2017; 98, 1666-77.

[23] RE Glasgow, EH Wagner, J Schaefer, LD Mahoney, RJ Reid and SM Greene. Development and validation of the Patient Assessment of Chronic Illness Care (PACIC). Med. Care 2005; 43, 436-44.

[24] EM Boger, M Hankins, SH Demain and SM Latter. Development and psychometric evaluation of a new patient-reported outcome measure for stroke self-management: The Southampton Stroke Self Management Questionnaire (SSSMQ). Health Qual. Life. Outcomes 2015; 13, 165.

[25] MW Post, H Boosman, MM van Zandvoort, PE Passier, GJ Rinke and JM Visser-Meily. Development and validation of a short version of the Stroke Specific Quality of Life scale. J. Neurol. Neurosurg. Psychiatr. 2011; 82, 283-6.

[26] D Hopper, J Coughlan and MR Mullen. Structural equation modeling: Guidelines for determining model fit. Elecron. J. Bus. Res. Meth. 2008; 6, 53-60.

[27] ME Sobel. Asymptotic confidence intervals for indirect effects in structural equation models. Sociol. Methodol. 1982; 13, 290-312.

[28] HF Chen, CY Wu, KC Lin, MW Li and HW Yu. Validity, reliability and responsiveness of a short version of the Stroke-Specific Quality of Life scale in patients receiving rehabilitation. J. Rehabil. Med. 2012; 44, 629-36. 
http://wjst.wu.ac.th

[29] SG Pedersen, GA Heiberg, JF Nielsen, O Friborg, HH Stabel, A Anke and C Arntzen. Validity, reliability and Norwegian adaptation of the Stroke-Specific Quality of Life (SS-QOL) scale. SAGE Open Med. 2018; 6, 1-10.

[30] K Sayuri and K Masako. Evaluation of health-related quality of life associated with provision of healthcare to stroke patients living at home in Japan. Health 2015; 7, 1105-13.

[31] G Musekamp, J Bengel, M Schuler and H Faller. Improved self-management skills predict improvements in quality of life and depression in patients with chronic disorders. Patient Educ. Couns. 2016; 99, 1355-61.

[32] R Reynolds, S Dennis, I Hasan, J Slewa, W Chen, D Tian, S Bobba and N Zwar. A systematic review of chronic disease management interventions in primary care. BMC Fam. Pract. 2018; 19, 11

[33] CE Fryer, JA Luker, MN McDonnell and SL Hillier. Self management programmes for quality of life in people with stroke. Cochrane Database Syst. Rev. 2016; 2016, CD010442.

[34] LW Green and M Kreuter. Health program planning: An educational and ecological approach. McGraw-Hill, New York, 2005.

[35] J Schmittdiel, DM Mosen, RE Glasgow, J Hibbard, C Remmers and J Bellows. Patient Assessment of Chronic Illness Care (PACIC) and improved patient-centered outcomes for chronic conditions. $J$. Gen. Intern. Med. 2008; 23, 77-80.

[36] T Deen, T Terna, E Kim, B Leahy and W Fedder. The impact of stroke nurse navigation on patient compliance postdischarge. Rehabil. Nurs. 2018; 43, 65-72.

[37] F Donald, K Kilpatrick, K Reid, N Carter, D Bryant-Lukosius, R Martin-Misener, S Kaasalainen, P Harbman, D Marshall and A DiCenso. Hospital to community transitional care by nurse practitioners: A systematic review of cost-effectiveness. Int. J. Nurs. Stud. 2015; 52, 436-51.

[38] AM Hamza, N Al-Sadat, L Siew Yim and NK Jahan. Predictors of poststroke health-related quality of life in Nigerian stroke survivors: A 1-year follow-up study. Biomed. Res. Int. 2014; 2014, 350281 .

[39] C Wanaratwichit, D Hills and M Cruickshank. Home-based care for people with disabilities: Role of registered nurses within the district health system in Thailand. Collegian 2020; 27, 18-22.

[40] BA Pramesona and S Taneepanichskul. Factors influencing the quality of life among Indonesian elderly: A nursing home-based cross-sectional survey. J. Health Res. 2018; 32, 326-33.

[41] DM Pindus, R Mullis, L Lim, I Wellwood, AV Rundell, NA Abd Aziz and J Mant. Stroke survivors' and informal caregivers' experiences of primary care and community healthcare services: A systematic review and meta-ethnography. PloS One 2018; 13, e0192533.

[42] J White, P Magin, J Attia, J Sturm, PM Elduff and G Carter. Predictors of health-related quality of life in community-dwelling stroke survivors: A cohort study. Fam. Pract. 2016; 33, 382-7.

[43] PKB Mahesh, MW Gunathunga, S Jayasinghe, SM Arnold and SN Liyanage. Factors influencing pre-stroke and post-stroke quality of life among stroke survivors in a lower middle-income country. Neurol. Sci. 2018; 39, 287-95. 